\title{
Broad inhibition of plasmodium falciparum cytoadherence by (+)-epigallocatechin gallate
}

\author{
Pradeep R Patil ${ }^{1,2,3}$, Sandra Gemma', Giuseppe Campiani ${ }^{1}$ and Alister G Craig ${ }^{2 *}$
}

\begin{abstract}
Background: The surface antigen PfEMP-1 is a key virulence factor of the human malaria parasite implicated in the cytoadherence of Plasmodium falciparum infected erythrocytes to a range of receptors on host endothelium. Among these host receptors, binding to ICAM-1 is related to cerebral malaria. The majority of the mortality in children with cerebral malaria is seen within $24 \mathrm{~h}$ of hospital admission despite the use of effective anti-parasite drugs, therefore, the development of adjunctive therapies is urgently needed.

The polyphenolic compound (+)-epigallocatechin gallate ((+)-EGCG) has been previously evaluated for antiadhesive properties using a small number of laboratory parasite isolates. Here, this property is further explored using a new panel of ICAM-1-binding patient isolates of $P$. falciparum to ascertain if (+)-EGCG might be effective as a broad spectrum inhibitor of ICAM-1-based cytoadherence.

Methods: Plasmodium falciparum lines, including A4 and ItG as positive controls and nine new ICAM-1 binding patient isolates, were allowed to bind with ICAM-1-Fc protein under static assay conditions in the presence and absence of $50 \mu \mathrm{M}(+)$-EGCG. Adhesion levels of all the parasite strains were quantified by microscopy as the mean number of infected erythrocyte (IE) bound per $\mathrm{mm}^{2}$ of surface area and statistical comparisons were made to demonstrate the effect of (+)-EGCG on the binding of various parasite variants to human ICAM-1.

Results: This study revealed that binding of patient isolates to ICAM-1 was reduced significantly with inhibition levels of $37 \%$ in patient isolate BC-12 up to a maximum of $80 \%$ in patient isolate 8146 at $50 \mu \mathrm{M}(+)$-EGCG.

Conclusion: Evaluation of the anti-adhesive property of (+)-EGCG against a new panel of ICAM-1-binding patient isolates of $P$. falciparum showed that this inhibitor, identified as potential mimic of the L43 loop of human ICAM-1, was effective at blocking cytoadherence.
\end{abstract}

Keywords: Plasmodium falciparum, Malaria, Cytoadherence, Inhibitor, ICAM-1

\section{Background}

Plasmodium falciparum malaria remains a major life-threatening parasitic disease, killing approximately 1 million people each year worldwide, mainly in sub-Saharan Africa [1]. Children and pregnant women are most susceptible. This infection can progress unpredictably to severe forms, including anaemia and cerebral malaria. The surface antigen PfEMP-1 ( $P$. falciparum erythrocyte membrane protein-1) is a key virulence factor of the human malaria parasite, encoded by about 60 var genes per haploid genome [2]. PfEMP-1 variants have been implicated in the

\footnotetext{
* Correspondence: agcraig@liv.ac.uk

2Liverpool School of Tropical Medicine, Pembroke Place, Liverpool L3 5QA, UK

Full list of author information is available at the end of the article
}

cytoadherence of P. falciparum-infected erythrocytes (IEs) to several binding receptors on host vascular endothelium [3-5], sequestering infected cells away from the spleen, which would otherwise destroy them. Switching of $v a r$ gene expression allows the parasite to modify the antigenic and functional properties of IEs, thereby evading immunity and affecting infection outcome. In most cases the parasite expresses a single var gene at a time, maintaining all other members of the family in a transcriptionally silent state [6].

Among the many host receptors, binding to Intercellular Adhesion Molecule -1 (ICAM-1) has been shown to be related to cerebral malaria [7]. The majority of the mortality with cerebral malaria is seen within $24 \mathrm{~h}$ of hospital admission despite the use of effective anti-parasite drugs [8], therefore, the development of adjunctive therapies is
Ciomed Central

(C) 2011 Patil et al; licensee BioMed Central Ltd. This is an Open Access article distributed under the terms of the Creative Commons Attribution License (http://creativecommons.org/licenses/by/2.0), which permits unrestricted use, distribution, and reproduction in any medium, provided the original work is properly cited. 
urgently needed. The polyphenolic compound (+)-epigallocatechin gallate $((+)$-EGCG) has been shown to have anti-adhesive properties [9]. This compound was identified using in silico molecular alignment techniques based on DE loop of human ICAM-1, which is a common feature of the ICAM-1 binding sites for at least the three P. falciparum laboratory variants tested [10]. (+)-EGCG inhibited binding of two variant ICAM-1 binding parasite lines at micromolar concentrations in a highly specific, dosedependent manner. Interestingly, binding to CD36 was partially inhibited by EGCG in an ICAM-1-binding line, but not in a laboratory isolate that showed no binding to ICAM-1. In this current study the anti-adhesive properties of (+)-EGCG were measured against a new panel of ICAM-1-binding patient isolates of $P$. falciparum in order to evaluate the breadth of the cytoadherence inhibitory effect.

\section{Methods}

Recombinant protein and cytoadherence inhibitor

(+)-EGCG, which is known to show anti-cytoadherence properties with A4 and ItG parasite strains, was used at $50 \mu \mathrm{M}$ concentration. The purified receptor protein used in this study was human ICAM-1-Fc, which was prepared as previously described [11].

\section{ICAM-1 selection of parasite lines using Dynabeads}

$50 \mu \mathrm{l}$ Protein A Dynabeads (Invitrogen) were washed 3 times with $500 \mu \mathrm{PBS} / 1 \% \mathrm{BSA}$ and then resuspended in $100 \mu \mathrm{l}$ PBS/1\%BSA. $2.5 \mu \mathrm{g}$ ICAM-1-Fc protein was added to the bead suspension and made up to $400 \mu \mathrm{l}$ by adding $\mathrm{PBS} / 1 \% \mathrm{BSA}$. This was then incubated at room temperature by rotating for $1 \mathrm{~h}$, again washed with 500 $\mu \mathrm{l}$ PBS/1\% BSA using a magnet to retain the beads each time. Beads were resuspended in $200 \mu \mathrm{l}$ PBS/1\% BSA and stored at $4{ }^{\circ} \mathrm{C}$ overnight.

Parasite culture was enriched for trophozoite stages using Plasmion by standard protocols [12]. $50 \mu \mathrm{l}$ of Plasmion enriched parasites and $150 \mu \mathrm{l} \mathrm{PBS} / 1 \%$ BSA were added to previously prepared ICAM-1 labelled Dynabeads. The mixture was incubated at room temperature, rotating for $45 \mathrm{~min}$ then gently washed twice with $500 \mu \mathrm{l}$ PBS/1\% BSA using a magnet to retain the beads each time. Beads were resuspended in parasite media and cultured with fresh washed red blood cells (RBCs).

\section{Parasite culture}

Plasmodium falciparum lines used in this study were the laboratory lines $\mathrm{A} 4$ and ItG, as a positive controls, and patient isolates PO-69, PCM-7, GL-6, BC-31, BC-12, $8206,8146,8131,6392$, which have previously been selected for binding to ICAM-1. Separate experiments had shown, using mutant ICAM-1 proteins, that all the ICAM-1-binding isolates used in this study have the L43 loop of ICAM-1 as a critical part of their binding site. To minimize the effect of antigenic switching in vitro the selected parasite lines were maintained in culture for not more than 3 weeks post-selection. RBCs for parasite culture were purified away from mononuclear cells and granulocytes using Lymphoprep.

Parasites were grown to maturity for 24-48 h from frozen stabilates. Laboratory parasite lines and parasites from patient isolates were cultured at $1 \%$ haematocrit in group $\mathrm{O}$ human erythrocytes using standard culturing techniques, using RPMI 1640 medium (supplemented with $37.5 \mathrm{mM}$ HEPES, $7 \mathrm{mM}$ D-glucose, $6 \mathrm{mM} \mathrm{NaOH}$, $40 \mu \mathrm{g}$ gentamicin sulfate $/ \mathrm{ml}, 2 \mathrm{mM} \mathrm{L}$-glutamine, and $10 \%$ human serum) at a $\mathrm{pH}$ of 7.2 in a gas mixture of $96 \%$ nitrogen, $3 \%$ carbon dioxide, and $1 \%$ oxygen. The parasitaemia was calculated by determination of the number of IEs per 500 red blood cells (RBC) for thin blood films. Baseline RBC counts were used to calculate the parasite density (parasites/ $\mu \mathrm{l}$ ). For all adhesion assays the IE suspension was adjusted to $3 \%$ parasitaemia and $1 \%$ haematocrit.

\section{Static adhesion assays}

Purified recombinant ICAM-1-Fc protein and PBS only (as negative control) were spotted in triplicate in a radial pattern using $2 \mu \mathrm{l}$ spots on $60 \times 50 \mathrm{~mm}$ bacteriological plastic Petri dishes (Falcon 1007; Becton Dickinson, Oxford, UK) at concentrations of $50 \mu \mathrm{g} / \mathrm{ml}$ for ICAM-1. This concentration had previously been shown to be within the dynamic range for detecting differences in adhesion and produce coated surfaces with receptors at levels approximately equal to receptor densities seen on activated endothelium [13]. The dishes were placed in a humidified chamber for $2 \mathrm{~h}$ at $37^{\circ} \mathrm{C}$ to allow the proteins to adsorb to the surface of Petri dish, after which the protein solution and PBS were aspirated off and the uncoated plastic area was blocked overnight with $1 \%$ $\mathrm{BSA} / \mathrm{PBS}$ at $4^{\circ} \mathrm{C}$. The plates were warmed at $37^{\circ} \mathrm{C}$ for one hour, blocking solution (1\% BSA/PBS) was removed and plates were washed with binding buffer (RPMI 1640 with $0.2 \%$ glucose) prior to adding $1.5 \mathrm{ml}$ of parasite culture (3\% parasitaemia; $1 \%$ haematocrit in binding medium), with and without $50 \mu \mathrm{M}(+)$-EGCG. The plates were incubated at $37^{\circ} \mathrm{C}$ for one hour with gentle resuspension every $10 \mathrm{~min}$. Unbound infected and uninfected erythrocytes were removed by gentle manual washing (4-6 washes) with $2 \mathrm{ml}$ binding medium per wash (monitoring of adhered cells was performed using an inverted microscope). The adhered IEs were fixed with $1 \%$ glutaraldehyde in phosphate buffered saline for $1 \mathrm{~h}$ and stained with $10 \%$ Giemsa for $30 \mathrm{~min}$. Adhesion levels of all parasite strains (with and without (+)-EGCG) were quantified by microscopy using a unique, anonymous identifier for each dish (with the operator blinded to the IE category) 
and results were expressed as the mean number of IEs bound per $\mathrm{mm}^{2}$ of surface area. Inhibition experiments were conducted twice for isolates PO-69, 8206 and 8131, and three times for the other parasite lines. The results were compared to quantify the effect of (+)-EGCG on binding of various ICAM-1-binding patient isolates to human ICAM-1.

\section{Results and discussion}

This study focussed on the ability of the naturally occurring polyphenolic compound (+)-EGCG to inhibit the binding of various patient isolates to ICAM-1. All the isolates tested showed significantly reduced adhesion with inhibition ranging from $37 \%-80 \%$ (Figure 1). This varying degree of inhibition of various patient isolates by (+)-EGCG, may refer to variable contact residues on PfEMP-1 of different patient isolates involved in the binding with ICAM-1 as seen in previous studies [10].

On the basis of these results it can be concluded that, despite the variation in the contact residues engaged on the BED side of ICAM-1 by different PfEMP-1 variants [14], some structural similarity is retained. It seems likely that the L-43 loop of human ICAM-1 is a key domain in the interaction with PfEMP-1 based on the observation that the whole set of ICAM-1 binding patient isolates was inhibited by $(+)$-EGCG, which is known to mimic L-43 loop of ICAM-1. Although several other binding activities use the N-terminal domain of ICAM-1 (e.g. T-cells, rhinovirus, fibrinogen), the L43 loop appears to be unique to $P$. falciparum-infected erythrocytes, supporting its use as a starting point for the design of specific inhibitors of cytoadherence. However, there are still a number of issues that still need to be resolved before taking (+)-EGCG further, such as its ability to reverse

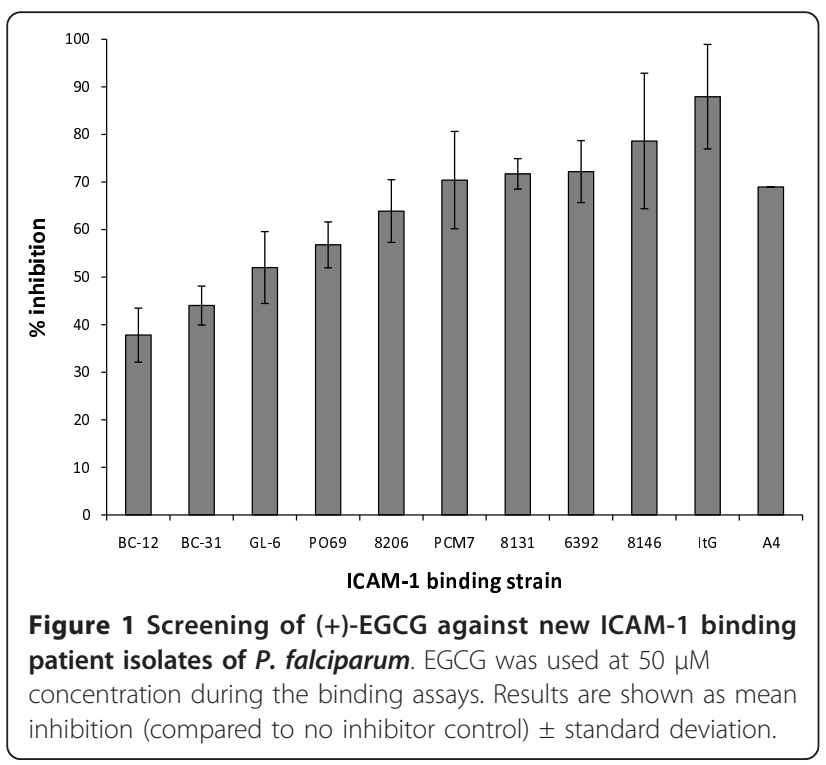

existing cytoadherence rather than just inhibition of new binding and testing the compound for disruption of ICAM-1-dependent IE binding in the context of endothelial cells. Also, to improve the pharmacological characteristics of (+)-EGCG, it is necessary to 'remake' the chemical scaffold to produce a lead structure that is more amenable to chemical synthesis. These experiments are underway.

\section{Conclusions}

$(+)$-EGCG is able to inhibit binding to ICAM-1 by a range of patient-derived parasite isolates. This supports further development of anti-adhesive compounds with broad reactivity based on this chemical scaffold as novel adjunct therapies for cerebral malaria.

\section{List of abbreviations}

BSA: Bovine Serum Albumen; EGCG: Epigallocatechin gallate; ICAM-1: Intercellular Adhesion Molecule - 1; IE: Infected erythrocyte; PBS: Phosphate buffered saline; PfEMP-1: Plasmodium falciparum erythrocyte membrane protein - 1; RBC: Red blood cell

\section{Acknowledgements}

Special thanks to Liverpool School of Tropical Medicine, Liverpool UK for providing lab facilities to carry out this research, the InterMalTraining International Ph.D. program for giving me this global atmosphere to contribute to this work and to Mr Tadge Szestak for providing the parasite isolates. Thanks also to the Marie Curie FP7 programme, under grant agreement n'PITN-GA-2008- 215281, and the Wellcome Trust for funding.

\section{Author details}

'European Research Centre for Drug Discovery and Development, Department of Pharmaceutical and Applied Chemistry, University of Siena, via Aldo Moro 2, Siena 53100, Italy. 'Liverpool School of Tropical Medicine, Pembroke Place, Liverpool L3 5QA, UK. ${ }^{3}$ Université Montpellier II Sciences et Techniques, Montpellier, France.

\section{Authors' contributions}

SG, GC \& AC designed the study; PRP carried out the experimental work; PRP \& AC wrote the manuscript; SG \& GC reviewed the final draft. All authors read and approved the final manuscript.

\section{Competing interests}

The authors declare that they have no competing interests.

Received: 12 September 2011 Accepted: 1 December 2011 Published: 1 December 2011

\section{References}

1. WHO: Severe falciparum malaria. World Health Organization, Communicable Diseases Cluster. Trans R Soc Trop Med Hyg 2000, 94(Suppl 1):S1-90.

2. Gardner MJ, Shallom SJ, Carlton JM, Salzberg SL, Nene V, Shoaibi A, Ciecko A, Lynn J, Rizzo M, Weaver B, Jarrahi B, Brenner M, Parvizi B, Tallon L, Moazzez A, Granger D, Fujii C, Hansen C, Pederson J, Feldblyum T, Peterson J, Suh B, Angiuoli S, Pertea M, Allen J, Selengut J, White O, Cummings LM, Smith HO, Adams MD, Venter JC, Carucci DJ, Hoffman SL, Fraser CM: Sequence of Plasmodium falciparum chromosomes 2, 10, 11 and 14. Nature 2002, 419:531-534.

3. Baruch DI, Pasloske BL, Singh HB, Bi X, Ma XC, Feldman M, Taraschi TF, Howard RJ: Cloning the $P$. falciparum gene encoding PfEMP1, a malarial variant antigen and adherence receptor on the surface of parasitized human erythrocytes. Cell 1995, 82:77-87.

4. Su XZ, Heatwole VM, Wertheimer SP, Guinet F, Herrfeldt JA, Peterson DS, Ravetch JA, Wellems TE: The large diverse gene family var encodes 
proteins involved in cytoadherence and antigenic variation of Plasmodium falciparum-infected erythrocytes. Cell 1995, 82:89-100

5. Smith JD, Chitnis CE, Craig AG, Roberts DJ, Hudson-Taylor DE, Peterson DS, Pinches R, Newbold Cl, Miller LH: Switches in expression of Plasmodium falciparum var genes correlate with changes in antigenic and cytoadherent phenotypes of infected erythrocytes. Cell 1995, 82:101-110.

6. Scherf A, Lopez-Rubio JJ, Riviere L: Antigenic variation in Plasmodium falciparum. Annu Rev Microbiol 2008, 62:445-470.

7. Ochola LB, Siddondo BR, Ocholla H, Nkya S, Kimani EN, Williams TN, Makale JO, Liljander A, Urban BC, Bull PC, Szestak T, Marsh K, Craig AG: Specific receptor usage in Plasmodium falciparum cytoadherence is associated with disease outcome. PLoS One 2011, 6:e14741.

8. Dondorp AM, Fanello CI, Hendriksen IC, Gomes E, Seni A, Chhaganlal KD, Bojang K, Olaosebikan R, Anunobi N, Maitland K, Kivaya E, Agbenyega T, Nguah SB, Evans J, Gesase S, Kahabuka C, Mtove G, Nadjm B, Deen J, Mwanga-Amumpaire J, Nansumba M, Karema C, Umulisa N, Uwimana A Mokuolu OA, Adedoyin OT, Johnson WB, Tshefu AK, Onyamboko MA, Sakulthaew T, Ngum WP, Silamut K, Stepniewska K, Woodrow CJ, Bethell D, Wills B, Oneko M, Peto TE, von Seidlein L, Day NP, White NJ, AQUAMAT group: Artesunate versus quinine in the treatment of severe falciparum malaria in African children (AQUAMAT): an open-label, randomised trial. Lancet 2010, 376:1647-1657.

9. Dormeyer M, Adams Y, Kramer B, Chakravorty S, Tse MT, Pegoraro S, Whittaker L, Lanzer M, Craig A: Rational design of anticytoadherence inhibitors for Plasmodium falciparum based on the crystal structure of human intercellular adhesion molecule 1. Antimicrob Agents Chemother 2006, 50:724-730.

10. Tse MT, Chakrabarti K, Gray C, Chitnis CE, Craig A: Divergent binding sites on intercellular adhesion molecule-1 (ICAM-1) for variant Plasmodium falciparum isolates. Mol Microbiol 2004, 51:1039-1049.

11. Craig AG, Pinches R, Khan S, Roberts DJ, Turner GD, Newbold Cl, Berendt AR: Failure to block adhesion of Plasmodium falciparum-infected erythrocytes to ICAM-1 with soluble ICAM-1. Infect Immun 1997, 65:4580-4585

12. Lelievre J, Berry A, Benoit-Vical F: An alternative method for Plasmodium culture synchronization. Exp Parasitol 2005, 109:195-197.

13. Gray C, McCormick C, Turner G, Craig A: ICAM-1 can play a major role in mediating $P$. falciparum adhesion to endothelium under flow. Mol Biochem Parasitol 2003, 128:187-193.

14. Chakravorty SJ, Craig A: The role of ICAM-1 in Plasmodium falciparum cytoadherence. Eur J Cell Biol 2005, 84:15-27.

doi:10.1186/1475-2875-10-348

Cite this article as: Patil et al:: Broad inhibition of plasmodium

falciparum cytoadherence by (+)-epigallocatechin gallate. Malaria Journal 2011 10:348

\section{Submit your next manuscript to BioMed Central and take full advantage of:}

- Convenient online submission

- Thorough peer review

- No space constraints or color figure charges

- Immediate publication on acceptance

- Inclusion in PubMed, CAS, Scopus and Google Scholar

- Research which is freely available for redistribution

Submit your manuscript at www.biomedcentral.com/submit 